\title{
Disaster Preparedness Impact In A Complex Ophthalmology Practice: A Review Of Patients Receiving Intravitreal Injections
}

This article was published in the following Dove Press journal:

Clinical Ophthalmology

\author{
Sophia El Hamichi \\ Aaron S Gold \\ Veronica Kon Graversen \\ Azeema Latiff \\ Timothy G Murray $\mathbb{D}$ \\ Murray Ocular Oncology and Retina \\ (MOOR), Miami, FL, USA
}

Correspondence: Sophia El Hamichi Murray Ocular Oncology and Retina (MOOR), 6705 Red Road, Suite 4I2, Miami, FL 33I43, USA

Tel $+|26755| 9677$

Email sophiaelhamichi@gmail.com
Purpose: A private tertiary care ophthalmology practice was analyzed to see how Hurricane Irma affected patient care.

Methods: Eighty-two patients (96 eyes) that missed their scheduled appointments due to Hurricane Irma were reviewed. Patients were being treated with intravitreal injection therapy for diabetic retinopathy, radiation retinopathy, vein occlusions, choroidal neovascularization, or neovascular age-related macular degeneration. The authors assessed patients' visual acuity and macular thickness changes before the hurricane and their initial visit after the storm. Emergency preparedness was also evaluated in this setting.

Results: Patients on average were delayed 19.6 days. On average, best-corrected visual acuity was 20/97 (0.7 logMAR) before the hurricane and 20/82 (0.6 logMAR) after the storm. The average central macular thickness change was $-1.30 \mu \mathrm{m}$. Intraocular pressure was not significantly affected and there were no ocular complications associated with the delay in therapy. A back-up electrical system was in place to maintain appropriate temperature for storage of medications and proper access to medical records.

Conclusion: The authors believe that minimizing delay in treatment was the most important contributing factor to preventing worsening of ocular disease. Ophthalmology clinics should strive for appropriate treatment modality regarding injection intervals prior to a natural disaster and emergency planning with excellent patient communication both before and after natural disasters.

Keywords: ophthalmology, intravitreal injections, hurricane, natural disaster, tertiary care

\section{Introduction}

Natural disasters have always been an inevitability in society and their impact on health cannot be measured immediately. In the Southeastern United States, hurricanes are currently the costliest natural disaster and they appear to be occurring more frequently than previous decades. Recently, hurricane Dorian ravaged the Bahamas, the direct effect on human loss and infrastructure damage is still being evaluated; also, in 2017 hurricane Maria devastated Puerto Rico. The direct damage wreaked havoc to the islands' infrastructure, but the indirect result of that damage played a significant role in the inhabitant's healthcare and life. The major hurricane to hit the US before Maria was Hurricane Irma.

Hurricane Irma was one of the strongest and costliest hurricanes (fourth costliest in America's history) in the Atlantic basin. It reached a Category 5 intensity on the 
Saffir-Simpson Wind Scale; however, after it made landfall in the Florida Keys, the intensity had weakened to category 4 and later on to Category 3 intensity when it reached Southeastern Florida on September 10th, 2017. ${ }^{1}$ Heavy rain and substantial flooding affected downtown Miami. Ten deaths were reported in the United States as directly related to the hurricane. Unfortunately, many more indirect deaths occurred. The real cost to healthcare is felt overtime and its ramifications may be seen for years.

Several studies have described the effects of natural disasters on emergency medicine; ${ }^{2}$ however, this report investigates the effects of an appropriately managed natural disaster on patient care in a tertiary clinical setting. In this setting, an ophthalmology practice focusing on retinal diseases and ocular neoplasms, emergency preparedness was analyzed to see how Hurricane Irma affected patient care.

\section{Methods And Materials}

Electronic medical records of patients that were rescheduled during Hurricane Irma were reviewed. All patients included in this review were being treated for various retinopathies, including but not limited to: diabetic retinopathy, radiation retinopathy, vein occlusions, choroidal neovascularization, or neovascular age-related macular degeneration (Figure 1). These are conditions that involve vascular activity in the retina. Treatment modality for vascular retinal disease has evolved over that last several decades. Laser ablation, cryotherapy, photodynamic therapy, and transpupillary thermotherapy are well-known strategies to treat anomalous vascular activity of the retina, these modalities are less frequently used today. Starting in the early 2000s, intravitreal injection therapy

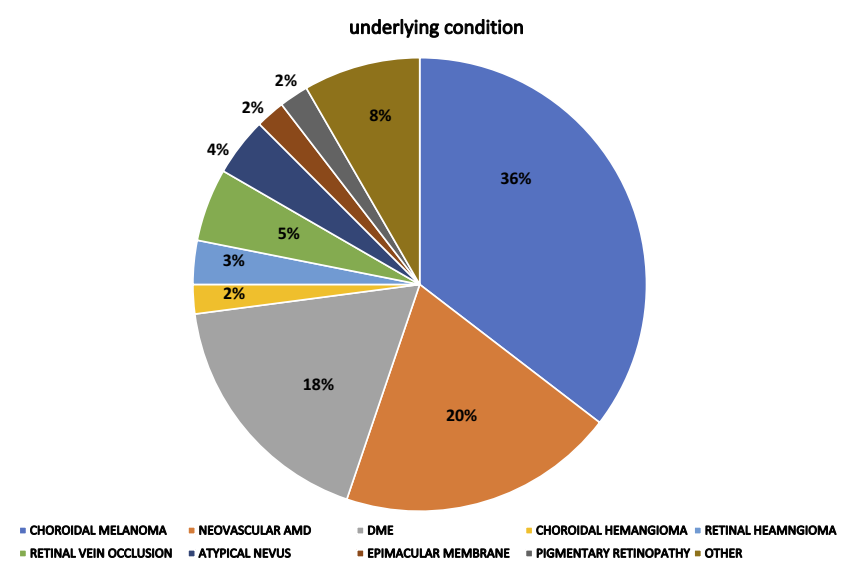

Figure I Pie chart distribution for underlying condition of patients that were rescheduled during Hurricane Irma. has become the most prevalent initial treatment for vascular and tumoral retinopathies. The main medications used in intravitreal injection therapy are anti-VEGF agents and steroids. Anti-VEGF medications need to be kept refrigerated at $2^{\circ} \mathrm{C}$ to $8^{\circ} \mathrm{C}$ until the expiration date. In this study, all patients were on a treatment schedule to receive intravitreal injection therapy with bevacizumab, aflibercept, or triamcinolone acetonide (Figure 2). A total of 205 patients missed their appointments while the office was closed due to the hurricane. All the patients were rescheduled, but patients that were currently not receiving intravitreal injection therapy were excluded from this review. Patients' visual acuity and macular thickness changes on spectral domain optical coherence tomography (SD-OCT) before Hurricane Irma and their initial visit after the storm were studied.

For the purpose of this review, the authors also assessed emergency preparedness plans to minimize the challenges following catastrophic events. This study is approved by Larkin Hospital Institutional Review Board, Miami, Florida, USA. The patient's consent waiver is assigned for retrospective studies. The patient's data confidentiality is respected, and this study is compliant with the Declaration of Helsinki.

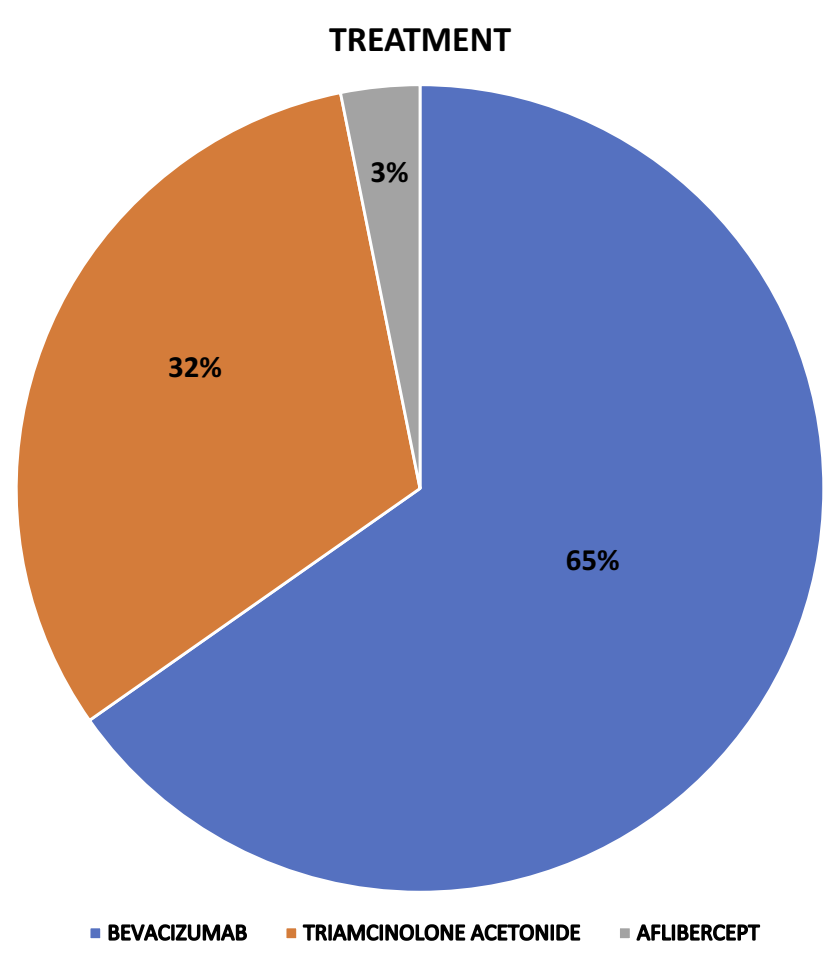

Figure 2 Pie chart distribution of treatment being utilized for patients before hurricane. 


\section{Results}

Eighty-two patients (96 eyes) were analyzed. There were 45 female (55\%) and 37 male (45\%) patients. Fifty-two right eyes and 43 left eyes were treated. The mean delay in treatment was 19.6 days (Figure 3). Prior to the storm, average best-corrected visual acuity was 20/97 (0.7 logMAR). Initial visits after the hurricane revealed patients' average visual acuity to be 20/82 (0.6 logMAR). Central macular thickness change was only $-1.30 \mu \mathrm{m}$. Intraocular pressure was not affected by the delay in care for these patients. There were no other ocular side effects related to the storm. Figure 2 shows the therapies used for the management of the ocular conditions: 62 eyes received Bevacizumab (65\%), 30 eyes received Triamcinolone (30\%), and 3 eyes were injected with Aflibercept (3\%).

In preparation for a natural disaster, our office is equipped with a back-up generator, located at the first floor of the building in a secure room. There was no power outage in the neighborhood aftermath of Irma. Therefore, Internet connection, phone lines, and electronic medical record access were possible. The medications (Anti-VEGF: Bevacizumab and aflibercept) were maintained at the appropriate temperature in the refrigerator. All medications, including Triamcinolone, did not expire during the acute crisis.

\section{Discussion}

Most of the time, storms result in injuries or fatalities; however, the potential hazards following the aftermath are more dramatic and can be catastrophic for human health.

Independently of the impact on eye health, disasters such as Irma can cause significant burden to private practices. To the best of the authors' knowledge, this is the first

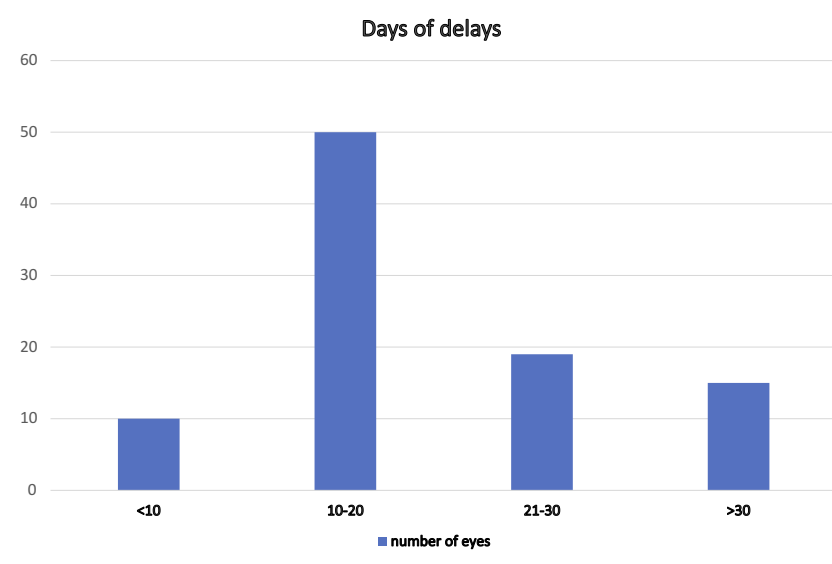

Figure 3 Patient delay distribution. report regarding natural disaster preparedness and its impact on ophthalmology practices. In this case, the patients that were rescheduled did not have an increase in ocular morbidity. Minimizing the delay in treatment was a key factor. Other factors that contributed to this outcome included minimal loss of electricity, prompt clearing of road debris, and good communication among the staff and patients. Although there cannot be a control arm for comparison in this unique review, based on previous studies assessing interval time between intravitreal injection therapy, we believe that any further delay in treatment would have significantly contributed to patients' loss of vision and/or worsening ocular anatomy. ${ }^{3,4}$ Intravitreal injection therapy has shown to keep visual acuity and macular anatomy stable in several studies. ${ }^{5-7}$ Additionally, appropriate treatment modality regarding injection intervals prior to the hurricane may have aided in improving outcomes despite the delay in therapy.

Other studies have also investigated the impact of natural disasters on patient care. ${ }^{8-13}$ One study showed that timely deployment of emergency team and preparedness plan greatly assisted in the effectiveness of care delivery for patients. ${ }^{8}$ Furthermore, the lack of preventable errors at hospitals can be attributable to strategic planning. The use of electronic health records has been reported to facilitate access to patient data and made rescheduling process easier. ${ }^{9}$ In large hospital centers, stocking up on medications and resources before the hurricane helped provide an adequate care the first few days after the storm. Whereas our clinical setting is smaller, deficit in preparation could have had a severe effect on the budget.

Since the use of electronic medical records, it has been clear that electricity and Internet connectivity are fundamental in today's health-care era. Access to medical history and contact information is of paramount relevance for treatment and management of simple and complex conditions. Private practice buildings should have a back-up electrical system that operates automatically, within seconds of a utility outage. Each refrigerator containing medications must have an accurate thermometer $24 \mathrm{hrs}$ a day. If a power outage affects the office, the medications that require specific temperatures might be lost, representing thousands of dollars lost. In addition, changes in temperature of these medications may also allow growth of microorganisms. If this occurs, and an intravitreal injection is performed, the morbidity is exponentially increased with risks of endophthalmitis and potentially blindness. 


\section{Conclusion}

This report exemplifies the importance of appropriate patient care before a natural disaster and the importance of patient communication and infrastructure repair immediately after the disaster. Furthermore, mastery of electronic health records facilitates access to patient data and minimizes delay in treatment.

\section{Disclosure}

Aaron S Gold reports personal fees from Regeneron, outside the submitted work. The authors report no other conflicts of interest in this work.

\section{References}

1. Cangialosi JP, Latto AS, Berg R. Hurricane Irma (AL112017). National Hurricane Center Tropical Cyclone Report; 2018.

2. Aiham Ghazali D, Guericolas M, Thys F, et al. Climate change impacts on disaster and emergency medicine focusing on mitigation disruptive effects: an international perspective. Int $J$ Environ Res Public Health. 2018;15(7):1379. doi:10.3390/ijerph15061188

3. Stacey AW, Demirci H. Serial intravitreal bevacizumab injections slow the progression of radiation maculopathy following iodine-125 plaque radiotherapy. Open Ophthalmol J. 2016;10:103-110. doi:10.2174/ 1874364101610010103

4. Shah NV, Houston SK, Markoe AM. Early SD-OCT diagnosis followed by prompt treatment of radiation maculopathy using intravitreal bevacizumab maintains functional visual acuity. Clin Ophthalmol. 2012;6:1739-1748. doi:10.2147/OPTH.S34949
5. Khan MA, Mashayekhi A, Shields JA, Shields CL. Intravitreal aflibercept as rescue therapy for post-radiation cystoid macular edema resistant to intravitreal bevacizumab: outcomes at 1 year. Ocul Oncol Pathol. 2017;3(4):313-319. doi:10.1159/000452163

6. Villegas VM, Gold AS, Wildner A, Latiff A, Murray TG. Intravitreal triamcinolone acetonide: a "real world" analysis of visual acuity, pressure and outcomes. Int $J$ Ophthalmol. 2016;9(5):789-791. doi:10.18240/ijo.2016.05.26

7. Kaplan RI, Chaugule SS, Finger PT. Intravitreal triamcinolone acetate for radiation maculopathy recalcitrant to high-dose intravitreal bevacizumab. Br J Ophthalmol. 2017;101(12):1694-1698. doi:10.1136/ bjophthalmol-2017-310315

8. Hoffman A, Fagan H, Casas-Melley A, et al. Hurricane irma impact on the inpatient population at a tertiary children's hospital in Florida. Am Surg. 2018;84(9):1395-1400.

9. Nix M, Caldwell D. Natural disasters: a Louisiana Gulf perspective of maintaining patient care. Clin J Oncol Nurs. 2018;22(4):460-463. doi:10.1188/18.CJON.460-463

10. Abolghasem Gorji H, Jafari H, Heidari M, et al. Cancer patients during and after natural and man-made disasters: a systematic review. Asian Pac J Cancer Prev. 2018;19(10):2695-2700. doi:10.22034/ APJCP.2018.19.10.2695

11. Sakuma A, Ueda I, Rengi S, et al. Increase in the number of admissions to psychiatric hospitals immediately after the Great East Japan Earthquake. Asia Pac Psychiatry. 2018;10(3):e12307. doi:10.1111/ appy. 12307

12. Izumikawa $\mathrm{K}$. Infection control after and during natural disaster. Acute Med Surg. 2019;6(1):5-11. doi:10.1002/ams2.367

13. Murakami N, Siktel HB, Lucido D, et al. Disaster preparedness and awareness of patients on hemodialysis after hurricane sandy. Clin J Am Soc Nephrol. 2015;10(8):1389-1396. doi:10.2215/CJN.1018 1014
Clinical Ophthalmology

\section{Publish your work in this journal}

Clinical Ophthalmology is an international, peer-reviewed journal covering all subspecialties within ophthalmology. Key topics include: Optometry; Visual science; Pharmacology and drug therapy in eye diseases; Basic Sciences; Primary and Secondary eye care; Patient Safety and Quality of Care Improvements. This journal is indexed on PubMed

\section{Dovepress}

Central and CAS, and is the official journal of The Society of Clinical Ophthalmology (SCO). The manuscript management system is completely online and includes a very quick and fair peer-review system, which is all easy to use. Visit http://www.dovepress.com/ testimonials.php to read real quotes from published authors. 